\title{
EL TRÉBOL DE CUATRO HOJAS. LA INTERNATIONAL PEASANT UNION Y SU ACTUACIÓN DURANTE LA GUERRA FRÍA'
}

\section{The four leaf clover. The International Peasant Union and its role during the Cold War}

\author{
MIGUEL CABO \\ Universidad de Santiago de Compostela \\ miguel.cabo@usc.es \\ Cómo citar/Citation \\ Cabo, M. (2018) \\ El trébol de cuatro hojas. \\ La International Peasant Union y su actuación durante la Guerra Fría. \\ Historia y Política, 40, 299-329 \\ doi: https://doi.org/10.18042/hp.40.11
}

(Recepción: 25/07/2017. Evaluación: 10/10/2017 Aceptación: 01/12/2017. Publicación: 02/11/2018)

\section{Resumen}

La International Peasant Union se fundó en Washington en 1947 para coordinar a los partidos agrarios de los países bajo dominio comunista en el Este y Centro de Europa. Desarrolló un abanico notable de actividades durante tres décadas,

1 Departamento de Historia, Universidade de Santiago de Compostela. Grupo de Referencia Competitiva del SUG HISTAGRA (ED431C 2017111). Este trabajo se inscribe dentro del proyecto «Los vectores del cambio estructural de las agriculturas atlánticas ibéricas: moto-mecanización y especialización lechera», referencia: HAR2016-77441-P (IP Lourenzo Fernández Prieto). Las traducciones son responsabilidad del autor. Quisiera hacer constar mi agradecimiento a José María Faraldo por sus útiles sugerencias a partir del primer borrador de este trabajo. 
manteniendo viva la ideología agrarista de la llamada Internacional Verde de Praga del periodo de entreguerras y al mismo tiempo movilizando todos los recursos disponibles a favor de Occidente contra la Unión Soviética. Los líderes agrarios exiliados proporcionaron una valiosa, aunque sesgada por sus duras experiencias personales y políticas, visión de la realidad del otro lado del telón de acero, en particular en sus campos de conocimiento (colectivización, políticas agrarias, etc.). La organización, ideología y actividades de la IPU son analizadas con detalle a través de fuentes impresas (en especial su boletín), archivísticas y bibliográficas.

\title{
Palabras clave
}

Guerra Fría; partidos agrarios; comunismo; Unión Soviética; totalitarismo.

\begin{abstract}
The International Peasant Union was founded in Washington in 1947 as an umbrella organization for the agrarian parties of the countries under Communist rule in Eastern and Central Europe. It developed a remarkable range of activities for three decades, keeping alive the peasantist ideology of the so-called Prague Green International between the wars and at the same time mobilizing every possible ressource for the triumph of the West against the Soviet Union. The exiled agrarian leaders provided a valuable, although biased by their hard personal and political experiences, insight into the reality behind the Iron Curtain, especially in fields related to their expertise (collectivization, agrarian policies and the like). The organization, ideology and range of activities of the IPU are explored at lenght using printed (particularly the IPU Bulletin), archival and bibliographical sources.
\end{abstract}

\section{Keywords}

Cold War; agrarian parties; communism; Soviet Union; totalitarianism. 
I. INTRODUCCIÓN. II. LOS ORÍGENES: LA INTERNACIONAL VERDE DE PRAGA (19211938) Y EL PERIODO BÉLICO. III. LA IPU: NACIMIENTO, ORGANIZACIÓN, FINANCIAMIENTO. IV. LA IDEOLOGÍA Y EL PROGRAMA DE LA IPU. V. INFLUENCIA Y ACTIVIDADES VI. EPÍLOGO. BIBLIOGRAFIA.

\section{INTRODUCCIÓN²}

El 4 de julio de 1947 los líderes de unos partidos de los que probablemente pocos periodistas presentes habían oído hablar nunca, provenientes de países que muchos no serían capaces de situar en un mapa y que hablaban inglés con el marcado acento de quienes han debido aprenderlo en la edad adulta, hicieron pública la denominada «Declaración del Día de la Independencia». La conferencia de prensa en un lujoso hotel de Washington tenía como fin dar a conocer la constitución de la International Peasant Union (IPU), como coordinadora de una serie de partidos agrarios de la parte de Europa que había caído bajo el control de la URSS tras el fin de la Segunda Guerra Mundial. Se trataba pues del punto de partida de una organización que iba a perdurar hasta los años setenta pero también de un punto de llegada, puesto que la trayectoria tanto de los partidos agrarios como de sus dirigentes se proyectaba bastantes años atrás en el tiempo y la IPU se concebía además como revitalización de la llamada Internacional Verde de Praga (1921-1938).

La declaración se resumía en cinco puntos: 1) los partidos agrarios como representación real de sus pueblos frente a los regímenes ilegítimos impuestos desde Moscú; 2) la defensa de la democracia en los términos definidos en la Carta del Atlántico y la de las Naciones Unidas; 3) la reivindicación de «la libertad individual y de la propiedad privada basada en el trabajo productivo" y de la conciliación de los intereses individuales y colectivos que encuentra su mejor expresión en el cooperativismo y su antítesis en la colectivización; 4) la exaltación del campesinado libre y próspero como «columna vertebral de las instituciones democráticas en nuestra parte del mundo», y 5) declaración de

2 Siglas usadas: BBIA (Bulletin du Bureau International Agraire); BDIC (Bibliothèque de Documentation Internationale Contemporaine, Nanterre); BUIP (Bulletin Union Internationale Paysanne); IPU (International Peasant Union); IPUMB (International Peasant Union. Monthly Bulletin). 
fe en la democracia, que es "una e indivisible», así como del pacifismo como principio rector de las relaciones internacionales. Lo firmaban líderes agrarios de Hungría, Croacia, Serbia-Yugoslavia y Bulgaria, y aclaraban que en la redacción habían participado también representantes rumanos y polacos ${ }^{3}$.

El presente trabajo se propone analizar la actividad de la IPU a través de fuentes hemerográficas, bibliográficas y archivísticas ${ }^{4}$, dado que ha recibido un escaso tratamiento historiográfico hasta el momento. En las obras dedicadas a su predecesora de Praga es mencionada a lo sumo como un colofón sin mayor trascendencia, aunque en los últimos años está comenzando a merecer la atención de algunos especialistas eslavos ${ }^{5}$. A través de ella será posible aproximarse desde una óptica original a la Guerra Fría desde sus inicios hasta la era Breznev.

\section{LOS ORÍGENES: LA INTERNACIONAL VERDE DE PRAGA (1921-1938) Y EL PERIODO BÉLICO}

Los partidos agrarios constituyen una familia política prolífica que alcanzó su época de mayor esplendor en el periodo de entreguerras en Escandinavia y los países de la Europa centro-oriental, si bien ya antes del cambio de siglo habían aparecido las primeras formaciones de este cariz, como el Venstre danés (1888), la Unión Agraria búlgara (1889), el Polskie Stronnictwo Ludowe (1895) en la Galizia austriaca o el Česká strana agrarní (1899) en Bohemia-Moravia $^{6}$. Será también en la década y media posterior a la Gran Guerra cuando alcancen mayores cotas de poder, con la formación de gobiernos en Bulgaria (1919) o Rumanía (1928) y de coaliciones con la socialdemocracia en los países nórdicos en los inicios de la Depresión. Mención aparte

\section{TIME International, 14-7-1947.}

4 La consulta de la prensa de la IPU ha sido posible gracias a la colección conservada en la Biblioteca Nacional Francesa y la Universidad de París X (Nanterre), así como numerosas publicaciones editadas por la misma y documentación de archivo, de la cual no obstante la mayor parte está disponible en internet en el archivo de la Stanford University (Hoover Fundation): https://bit.ly/2NmeQSl.

5 Así, Valota Cavallotti (1987: 198) la caracterizaba como «un puñado de hombres derrotados e impotentes». La única visión general la constituye el trabajo de Arkadiusz Indraszczyk (2013) como capítulo dentro de un libro dedicado a los exiliados de Europa oriental, a lo que habría que sumarle los breves textos de Stepka (2015) y Swacha (2015) y una tesina inédita (en checo) que trata la IPU en un apartado para contextualizar la represión del partido agrario en Checoslovaquia; Smutný (2010): 43-68.

6 Sobre los partidos agrarios las visiones más completas siguen siendo las de Gollwitzer (1977) y Urwin (1980). Para un estado de la cuestión reciente, Cabo (2018). 
merece lo sucedido en Checoslovaquia, donde el Partido Agrario Republicano fue el partido predominante durante toda la I República. La implantación de sucesivas dictaduras y la expansión nazi marcan un retroceso que culminará en 1945-48 cuando la mayor parte termine siendo disuelta en las nacientes «democracias populares». Si bien es cierto que en algunas de ellas existieron partidos agrarios como brazos auxiliares de los partidos comunistas a la hora de facilitar el control de la población rural y la aceptación de la colectivización agraria, en ningún caso se pueden considerar continuadores de los partidos agrarios de preguerra. De hecho, en el discurso oficial de las denominadas democracias populares estos fueron condenados como filofascistas, burgueses y contrarrevolucionarios, como prolongación de las críticas tradicionalmente expresadas desde los partidos comunistas y la Krestintern o Internacional Comunista Campesina activa en Moscú entre 1923 y 1932 $2^{7}$. Mientras en la Europa meridional y occidental los partidos agrarios no pasaron de ser actores secundarios en el mejor de los casos, Escandinavia se convirtió en el reducto de este tipo de formaciones, que mantuvieron un peso electoral más que respetable hasta que el retroceso de la población activa agraria les obligó a reinventarse como partidos de centro.

Los partidos agrarios, pese a su diversidad, presentaban una serie de rasgos comunes y un sustrato ideológico lo suficientemente compartido como para facilitar contactos e influencias mutuas que se formalizaron en la denominada Internacional Verde ${ }^{8}$. En efecto, en 1921, aprovechando la coyuntura de la visita del carismático líder agrario y en esos momentos jefe de gobierno búlgaro Aleksandar Stambolijski, tuvo lugar la constitución de la Oficina Agraria Internacional en Praga, bajo el ala protectora del partido agrario checoslovaco. Allí pasó a celebrarse un congreso anual y a editarse con periodicidad trimestral a partir de octubre de 1923 su órgano de prensa ${ }^{9}$. La cara visible era Antonin Svehla (1873-1933), jefe de Gobierno entre 1920 y 1926. Sin embargo, el responsable de la gestión práctica de la Oficina y de la dirección del boletín a partir de 1927 fue Karel Mečír (1886-1947), que había sido embajador en Atenas y Bruselas y supo atenuar los ribetes paneslavistas para facilitar el ingreso de partidos de todo el continente ${ }^{10}$.

7 La obra de referencia sigue siendo la de Jackson (1966). Pueden consultarse más recientemente las alusiones contenidas en Borrás et al. (2008): 5-7, y Vigreaux (2012).

8 Haushofer (1977); Valota (1987), y Kubu y Sousa (2010).

9 A partir de 1927 se impuso un formato trilingüe en francés, checo y alemán. En el primer idioma su título era Bulletin du Bureau international agricole y a partir de 1928 la última palabra se sustituyó por agraire.

10 Smutný (2010): 34. 
La Oficina coordinaba a partidos muy dispares, desde aquellos que ocupaban posiciones de poder en sus respectivos países a los que ejercían la oposición, otros de peso marginal y restos de los que habían sido prohibidos tras la instauración de dictaduras. Una ausencia debilitadora fue la de los partidos nórdicos (a excepción del finlandés). El Partido de los Pequeños Campesinos húngaro tampoco se integró, probablemente por reticencias antieslavas y por juzgarla un instrumento de la política exterior checa y en segunda instancia francesa. Sí se adhirieron algunos partidos de Europa occidental, aunque marginales o secundarios en sus sistemas políticos ${ }^{11}$. En 1929 la Oficina Internacional Agraria celebró una asamblea con representación de diecisiete partidos que establecieron dieciséis puntos programáticos de obligada obediencia para ser aceptado como miembro: fomento del cooperativismo (con mención expresa al modelo danés), promoción de la democracia parlamentaria, pacifismo en política exterior, defensa de la explotación familiar, etc. ${ }^{12}$. Tras alcanzar su punto álgido hacia 1930, la Internacional Verde comenzó a sufrir los efectos de la progresiva instauración de dictaduras fascistas o fascistizadas con la consiguiente ilegalización de los partidos que la componían hasta su cierre finalmente en 1938. El último editorial de su boletín levantaba acta de la desaparición de la misma «por lo que parece durante un período prolongado» una vez convertido en inviable el país que se había convertido en "Meca del agrarismo»"

Durante la Segunda Guerra Mundial los partidos agrarios del Centro y Este de Europa cesan su actividad y sus líderes pagan un pesado tributo en forma de ejecuciones, encarcelamientos y exilio bajo la ocupación alemana o los gobiernos en la órbita del III Reich. Aunque se dieron casos de colaboracionismo, no fueron representativos de la actitud mayoritaria, si bien ahí radicaría uno de los argumentos más recurrentes en la propaganda comunista una vez terminado el conflicto. De hecho, al partido agrario con más ascendiente y mayor experiencia de poder, el checoslovaco, se le prohibió reorganizarse con el discutible argumento de que un Gobierno en el que era mayoritario había aceptado la desmembración del país en 1938, acusación que también justificaría las condenas a muchos de sus dirigentes, como la del sucesor de Svehla al frente del partido y exprimer ministro Rudolf Beran (1887-1954) ${ }^{14}$.

11 Partidos agrarios de Bélgica, Grecia (efímeramente en 1930-31), Países Bajos y Suiza y el más activo, el Parti agraire et paysan français. Tardíamente, en 1934, se acepta la incorporación del Partido Agrario Español.

12 BBIA II, 1929, p. 99.

13 BBIA IV, 1938, pp.129-131.

14 En un artículo titulado «In the Interest of Truth» el representante checo en la IPU Josef Cerny reacciona ante las afirmaciones de algún historiador al respecto, 
Durante la guerra numerosos líderes de los partidos agrarios se refugian en Londres y se crean así las condiciones para retomar los contactos, preparar la reconstitución de sus partidos llegado el momento propicio y planificar las reformas a llevar a cabo en sus países tras el conflicto. Ya en otoño de 1940 se crea bajo los auspicios del Fabian Society International Bureau el East European Discussion Group, con la participación de políticos agrarios de relieve como el polaco Jerzy Kuncewicz o el serbio Milan Gavrilovic. Allí comienza a plasmarse una aspiración que constituirá uno de los pilares del programa de la IPU: la formación de una confederación de países de Europa central y oriental que a su vez constituiría una contribución hacia la unión europea y la prevención de futuras guerras ${ }^{15}$. Los debates se prolongan en el seno del think tank de política internacional Chatham House, moderados por el historiador experto en Europa del Este Robert William Seton-Watson (1879-1951), el politólogo rumano-británico David Mitrany (1888-1975) y el alto funcionario y político liberal Frederick Whyte (1883-1970) y fructifican en una Conferencia Agraria Internacional celebrada el 9 de julio de 1942. En ella se proclaman el rechazo de toda forma de dictadura, la adhesión a los principios de la Carta del Atlántico y unas pautas generales para las reformas agrarias que se deberían desarrollar al término de la guerra. Los trabajos de dicha conferencia fueron publicados dos años después bajo el título Agrarian problems from the Baltic to the Aegean. Aunque agrupase a politicos de diferentes partidos, los agrarios también estaban presentes en el Danubian Club, formado en 1942 bajo amparo fabiano con representantes albaneses, austríacos, búlgaros, checoslovacos, húngaros, griegos, polacos, rumanos y yugoslavos.

Es por tanto en Reino Unido donde en cierto modo encuentra continuidad durante la guerra la Internacional Verde de Praga. De hecho, el citado Agrarian problems from the Baltic to the Aegean elabora ideas y proyectos que ya venían de las dos décadas anteriores y que encontraremos en la IPU a partir de 1947: la apuesta por una propiedad campesina viable a través del cooperativismo, el apoyo firme del Estado (crédito público, regulación de precios mínimos...), mejoras técnicas, una industrialización enraizada en los recursos agrarios y forestales, etc.

reivindicando el papel histórico del Partido Agrario como impulsor del parlamentarismo, sostiene que los colaboracionistas fueron muy escasos y culpa a los comunistas pero también a la complicidad de Benes (en lo que parece una prolongación de ciertas disputas entre los exiliados de su país durante la guerra) de haber prohibido su partido porque sabían que era el más serio obstáculo para la toma del poder. IPUMB V, 1956, pp. 9-12.

15 Rutaj (1948): 9. 
Una vez rematado el conflicto bélico parecía llegado el momento de recuperar el papel preponderante jugado en el pasado, pero el contexto exigió la colaboración con los partidos comunistas en coaliciones de gobierno en los países para los cuales los Acuerdos de Yalta habían sancionado la preponderancia de la influencia soviética. Los partidos agrarios siguieron en la mayor parte de los casos un recorrido marcado por las tres fases de la estrategia comunista para la toma del poder señaladas por la historiografía: frentes nacionales, peso cada vez más desequilibrado a favor del partido comunista y por último instauración de un régimen dictatorial. De poco sirvieron su notable base social y los favorables resultados electorales allí donde se dieron inicialmente las condiciones para un escrutinio limpio, como fue el caso del Partido de los Pequeños Cultivadores húngaro, que en noviembre de 1945 acaparó un $57 \%$ de los votos, superando ampliamente el $17 \%$ del partido comunista. Una combinación de violencia, fraudes electorales, presiones y persuasión, más el irrebatible factor geopolítico de la cada vez más inapelable división del continente culminaron con la toma del poder en solitario por los partidos comunistas, consumada con el golpe de Estado en Checoslovaquia en febrero de $1948^{16}$. En dicho proceso los aparentemente poderosos partidos agrarios fueron sucumbiendo y pagaron un alto precio en forma de condenas de prisión, ejecuciones y exilios, aunque no faltó tampoco quien optase por colaborar con el nuevo orden de cosas.

La ideología agraria y los partidos que la habían encarnado parecían por tanto una vía muerta, una inviable nostalgia ante la modernización impulsada bajo el modelo colectivista e industrializador soviético. Y sin embargo, como los restos de un naufragio, los líderes agrarios supervivientes de la debacle fueron convergiendo en distintas capitales europeas y finalmente de forma definitiva en Estados Unidos para intentar insuflar nueva vida a sus ideales.

\section{LA IPU: NACIMIENTO, ORGANIZACIÓN, FINANCIAMIENTO}

La aspiración a refundar la Internacional Verde de entreguerras estaba ya presente desde su disolución; de hecho, tras la liberación de sus respectivos países el búlgaro Giorgi M. Dimitrov (1903-1972) y el rumano Ion Mihalache (1882-1963) firmaron una declaración en nombre de sus respectivos partidos comprometiéndose a colaborar entre sí y a ampliar su acuerdo a los partidos

16 Trabajos recientes sobre este tema serían los de Gaddis (2008); Tismaneanu (2009); Applebaum (2014), o Leffler y Westad (2011). Una reflexión sobre el papel de la violencia en dicho proceso la ofrece Faraldo (2014). 
agrarios de otros países ${ }^{17}$. Será Dimitrov el desencadenante del proceso al ser también el primero de los líderes agrarios que deba abandonar su país por su negativa a integrar su formación en un Frente Nacional con los comunistas. Tras abandonar Bulgaria gracias a la ayuda de la embajada estadounidense, recala en Italia, donde contacta con el embajador polaco, Stanislaw Kot, dirigente del Partido Campesino, y a través de él transmitió un mensaje a Stanislaw Mikołajczyk (1901-1966) ${ }^{18}$. Mikołajczyk era el máximo líder del partido campesino polaco y en ese momento ministro de Agricultura en un Gobierno de coalición. Dimitrov hizo gala de pesimismo y dotes proféticas a partes iguales, puesto que auguró que en Polonia el partido agrario también terminaría por ser desmantelado y le sugirió que hiciese preparativos para su supervivencia.

Dimitrov llega en enero de 1946 a Estados Unidos y mantiene una reunión con altos funcionarios del Departamento de Estado en la que se le recomienda mantener un perfil bajo en sus actividades políticas. Aunque descontento con lo que consideraba un reflejo de la actitud conciliatoria con la URSS, atendió el consejo, en parte también por no exponer a sus seguidores en Bulgaria a ulteriores represalias, lo cual no le impidió entrevistarse con miembros del Congreso. En septiembre de 1946 el croata Vladko Macek visita Pittsburgh desde su exilio en París para establecer contactos con la colonia emigrante y Dimitrov se reúne con él, y ante el deterioro de las relaciones entre las dos superpotencias creen llegado el momento de preparar la reconstitución de la Internacional Agraria. El húngaro Ferenc Nagy se les une en junio de 47, y Dimitrov redacta una declaración a la que se adhiere Gavrilovic por telegrama desde Londres en representación del Partido Campesino Serbio que se convertiría en la Declaración del Día de la Independencia que marcaría la presentación en sociedad de la IPU. A continuación siguió un goteo de incorporaciones al ritmo de los acontecimientos al otro lado de lo que acababa de ser bautizado como el telón de acero. En enero de 1948 Mikołajczyk llega a EE. UU. y se adhiere, al igual que había hecho poco antes el líder del Partido Nacional Agrario Rumano Iuliu Maniu (que poco después sería encarcelado y moriría en prisión) a través de un enviado.

La IPU quedó plenamente configurada en su primer congreso, celebrado en Washington del 24 al 27 de mayo de $1948^{19}$. El congreso sería el máximo

17 Union International Paysanne (1950): 13. No debe confundirse a G.M. Dimitrov con Georgi Dimitrov Mihaylov (1882-1949), figura prominente de la Internacional Comunista y primer ministro entre 1946 y su fallecimiento en 1949.

18 Véase Moser (1979: 261 y ss.) para la reconstrucción de los primeros años de Dimitrov en el exilio.

19 Union International Paysanne (1950). 
órgano de la IPU, compuesto por delegados de cada partido miembro y responsable del programa, los estatutos y la aceptación de nuevas incorporaciones. El congreso asumirá en realidad una finalidad básicamente ceremonial de cara a la opinión pública, será el momento de captar la atención de los medios de comunicación, remachar los principales puntos programáticos y situar en un primer plano bien visible los apoyos de que se disponía con la asistencia de figuras destacadas de la Administración y el Congreso, dirigentes de las organizaciones agrícolas estadounidenses y personalidades políticas extranjeras. A lo largo de su historia la IPU celebraría nueve congresos, los tres primeros en Washington (1948, 1950 y 1952), el cuarto en Nueva York (1954), el quinto en París (1956), centrado en la crisis de Hungría, el sexto (1959), séptimo (1961) y octavo (1964) en Washington y el noveno y último en Nueva York en 1969.

Entre congresos la organización sería gestionada por un comité central radicado en Washington, con un delegado por partido, un presidente (el polaco Mikolajczyk sería elegido unánimemente al igual que el resto de los cargos), un secretario general (Dimitrov) y cuatro vicepresidentes (Ferenc Nagy, Vladko Macek, Milan Gavrilovic y Augustin Popa), todos ellos elegidos durante los congresos. El Comité Central era el ámbito donde se tomaban las decisiones trascendentales, puesto que los estatutos le reconocían la capacidad de arrogarse funciones propias del congreso siempre que las sometiese a su ratificación en el siguiente que se celebrase. El presidente, el secretario general y los cuatro vicepresidentes constituían el Comité Ejecutivo, cuyas funciones no quedaban claramente deslindadas de las del Comité Central en los estatutos y, como afirma Indraszczyk, parece haber funcionado como un presidium dentro del mismo (no deja de resultar paradójico que esta terminología remita al lector irremediablemente al PCUS, siendo la IPU una organización ferozmente anticomunista) ${ }^{20}$. El organigrama de la IPU mostraba una clara continuidad con el de su antecesora, salvo que en esta había dos vicepresidentes en vez de cuatro ${ }^{21}$. Para gestionar el día a día de la IPU en el primer congreso se crea una serie de comisiones, en concreto las de demandas (para examinar las solicitudes de ingreso de nuevos partidos miembros), la de protección y asistencia a refugiados, la de publicaciones, la de asuntos exteriores, la de problemas agrarios, la de derechos del hombre y la de control. Con posterioridad se añadirán las de juventud y mujeres.

20 Indraszczyk (2013): 199.

21 BBIA II, 1929, p. 100. Esa continuidad no se daba en el plano personal puesto que solamente el croata Macek estaría presente en los órganos ejecutivos de la Oficina de Praga y la IPU, aunque otros dirigentes habían desempeńado funciones menores en aquella. 
La IPU tendrá su sede en Washington, pero contará con varias delegaciones en el extranjero que tendrán como misión coordinar la ayuda a los exiliados en su territorio de influencia, recopilar información sobre los acontecimientos al otro lado del telón de acero y defender las tesis de la IPU ante la opinión pública y los gobiernos en cuestión. A partir del primer congreso (Washington 1948) se irán constituyendo en Londres, París, Estrasburgo, Roma, Ginebra, Bonn, Múnich y Estocolmo, además de sendas delegaciones en Nueva York y Chicago. A partir de 1950 editará su boletín (durante los primeros años también con una versión en francés), en cuya cabecera aparecía el mismo símbolo, un trébol de cuatro hojas, que en el publicado hasta $1938^{22}$. El boletín no estaba fundamentalmente destinado al público, sino a ser distribuido entre los partidos miembros, partidos políticos y funcionarios de diferentes países.

El sostenimiento de una organización permanente, la edición del boletín mensual y numerosos libros y folletos, los viajes de los dirigentes para participar en diferentes foros en EE. UU. y el extranjero... todo ello suponía lógicamente unos gastos considerables. Ni en el boletín ni en la documentación conservada en el archivo de la Universidad de Stanford ni en las actas de los congresos se ofrecen datos sobre el presupuesto anual ni las fuentes de ingresos. En teoría estos provenían de los partidos afiliados y de donativos. Las memorias de algunos de sus dirigentes hacen mención a las ganancias provenientes de sus conferencias, artículos en prensa y de los derechos de autor de sus libros, pero es improbable que todo ello cubriese un porcentaje sustancial de las necesidades de la organización. Aunque sin poder precisarlo con demasiado detalle, tanto la bibliografía disponible como documentos consultables en la red apuntan a subvenciones provenientes de la Administración estadounidense a través del Free Europe Committee, el Departamento de Estado y la CIA, al igual que a otras muchas organizaciones, para sufragar lo que Saunders (2001) ha denominado "guerra fría cultural»" En su informe ante el cuarto congreso (1954), el secretario Dimitrov afirma sin más precisiones que desde el anterior las dificultades financieras habían obligado a despedir a la mayor parte de los empleados retribuidos, a reducir la tirada del boletín de seis mil a mil ejemplares y a que su circulación pasase de mensual a bimensual,

22 Durante un periodo que no podemos precisar se publicó también con periodicidad trimestral en Bonn una publicación en alemán (Agrarpolitische Rundschau) con una selección de los materiales del boletín, según se deduce de una mención en el último número del boletín; IPUMB, «To Our Friends», 1971, p. 3.

23 Simpson (1988): 202; Indraszczyk (2013): 199; Ruschke (2015): 162, y Smutný (2010): 64-66. 
además de poner fin a su versión en francés. Sin embargo, a partir de agosto de 1953 habían elaborado un nuevo presupuesto con mayores ingresos, de los que no aclaraba la procedencia, y podían permitirse recuperar la periodicidad mensual y contratar nuevo personal administrativo ${ }^{24}$.

El financiamiento siempre fue uno de los talones de Aquiles de la IPU en dos sentidos. En primer lugar, ofrecía un flanco débil para las críticas de sus oponentes, de manera que oficialmente sus líderes siempre negaron recibir fondos públicos ${ }^{25}$. En segundo lugar, cuando la línea dura inflexible con el comunismo propia de la IPU no estaba en sintonía con la política predominante en la Administración estadounidense, su autonomía se veía mediatizada, como sucedió con las presidencias demócratas en los años sesenta cuando la restricción de los fondos obligó a una moderación en sus posicionamientos públicos ${ }^{26}$.

Fuese como fuese, la IPU había quedado plenamente configurada en el momento del inicio de la Guerra Fría, y si bien es cierto que los partidos que la formaban habían perdido el poder efectivo una vez implantados los regímenes comunistas en el Centro y Este de Europa, todavía tenían activos considerables en su favor, como se mostrará en el apartado quinto. A la altura de su segundo congreso (1950) habían ingresado en ella once partidos agrarios de Albania, Bulgaria, Croacia, Estonia, Hungría, Lituania, Polonia, Rumanía, Eslovaquia, Checoslovaquia y Yugoslavia-Serbia, a los que se sumarían después el letón y finalmente, en 1964, el ucraniano, cuyo ingreso se había retrasado una década puesto que existían disputas entre los exiliados en torno a quién debía ostentar su representación ${ }^{27}$. El segundo artículo de los estatutos establecía que cada «nación» solamente estaría representada por un partido (el mismo punto existía en la Internacional de Praga, aunque se permitían

24 IPUMB XI-XII, 1954, p. 22.

25 Ya desde el primer momento, por ejemplo cuando al poco de su fundación Dimitrov compareció ante el Comité de Actividades Antiamericanas, a lo que se hará mención más adelante, y sostuvo que la IPU se sostenía exclusivamente con donaciones privadas y de los partidos afiliados, apuntando a que de hecho su mujer había tenido que aceptar un empleo. Hearings before the Subcommittee on Legislation of the Committee on Un-American Activities. House of Representatives. Eigthtieth Congress. Second Session on H.R. 4422 and H.R. 4581 (1948), p. 327. Sin embargo, a los pocos meses de fundarse la IPU Constantine Poulos (1916-1986), un antiguo corresponsal de guerra en los Balcanes y simpatizante comunista según Moser (1979: 277), tildaba a Dimitrov en un artículo en The Nation de "oportunista» y "reaccionario" al tiempo que cuestionaba sus «oscuras» fuentes de financiación.

26 Moser (1979): 285.

27 IPUMB XI-XII, 1954, p. 22. 
excepciones con el acuerdo del resto de los partidos miembros), de manera que la existencia de más de una formación para Checoslovaquia, Yugoslavia y por supuesto la URSS suponía una desautorización ańadida al orden impuesto al este del Elba tras la Segunda Guerra Mundial.

Todos los partidos que formaban parte de la IPU habían existido antes de la Segunda Guerra Mundial, aunque con notables diferencias en su implantación social y experiencia de gobierno, excepto dos de ellos. En el periodo de entreguerras checos y eslovacos habían estado agrupados en la misma formación, el poderoso Partido Agrario Republicano, del que era vicepresidente Milan Hodza (1878-1944), que también llegó a ser presidente de la Internacional Verde de Praga. Su hijo Fedor (1912-1968), ministro de Agricultura y Asuntos Exteriores del Gobierno checoslovaco en el exilio, ocupó la Secretaría General del Partido Democrático (eslovaco), que se formó en el contexto del levantamiento de 1944 como aglutinador de los elementos de la oposición antifascista no comunistas. Fue el más votado en Eslovaquia en las elecciones de 1946, pero fue disuelto en 1948 y se reconstituyó en el exilio integrándose en la IPU, del que Fedor Hodza formaba parte, en el Comité Central, en representación de su partido pese a que su carácter agrario era discutible ${ }^{28}$. En cuanto al caso ucraniano, un partido agrario ucraniano de escaso peso había existido durante los ańos veinte en Polonia, pero no existen precedentes, como es lógico en los territorios ucranianos dentro de la URSS. En 1954 el profesor de la Universidad jesuita de Marquette (Wisconsin) Roman Small-Stocki solicita el ingreso en la IPU en representación del Partido Campesino Ucraniano ${ }^{29}$. Sin embargo, no se plasmará hasta diez años después por disputas internas entre sus componentes. Sabemos que en 1962 apareció (editado en Londres) el primer número de Nove selo (La nueva aldea) como órgano del Partido Agrario Ucraniano en el exilio, pero apenas conocemos menciones de la actividad de un partido que parece haber sido meramente coyuntural por parte de exiliados ucranianos para estar presentes en los foros animados por la IPU.

Al contrario que su predecesora de entreguerras, la IPU no incorporará partidos agrarios escandinavos ni occidentales. No obstante, mantendrá relaciones estrechas con formaciones como la Confederazione Nazionale Coltivatori Diretti (próxima a la DC) o el Parti Paysan francés y, algo que nunca hizo la Internacional de Praga, con partidos de otros continentes, en especial China e India. El resultado fueron conferencias y seminarios en Asia o Latinoamérica y una amplia cobertura en su boletín, a partir de mediados de los

28 El obituario de Fedor Hodza en IPUMB I-XII, 1968, p. 12.

29 IPUMB XI-XII, 1954, p. 22. 
cincuenta, de la cuestión agraria en otros continentes, mayoritariamente al compás de los avatares de la política internacional (China, Corea, Cuba, Vietnam), puesto que uno de los dogmas de la IPU era la conexión directa entre las características del campesinado en un territorio y las posibilidades de que una revolución comunista se impusiese.

\section{LA IDEOLOGÍA Y EL PROGRAMA DE LA IPU}

Desde el punto de vista ideológico la IPU presentaba un alto grado de continuidad con la Internacional de Praga, de la que se proclamaba heredera. No obstante, el diferente contexto histórico y las circunstancias de los partidos que las componían explican algunas diferencias y matices que requieren ser resaltados. La ingente actividad publicística de la IPU a lo largo de varias décadas constituye un corpus teórico y programático que para ser presentado de forma manejable podemos sintetizar en tres puntos: 1) la concepción de la que se partía de la propia organización y los partidos miembros, su misión histórica si se quiere; 2) la visión de la agricultura y el campesinado, su papel en el mundo contemporáneo y sus implicaciones en todos los órdenes, y por último 3) la interpretación que se hace del comunismo como antagonista por excelencia no solamente de la IPU, sino del campesinado y de todo lo que representaba.

Comenzando por el primer punto, desde la IPU se va a llevar a cabo una reivindicación constante de la trayectoria de los partidos agrarios, de sus líderes y de la Internacional Verde. Adopta formas variadas, desde biografías hagiográficas de los fundadores hasta obituarios de aquellos líderes que iban falleciendo bien en el exilio bien víctimas de la represión en sus países de origen, pasando por actos de homenaje en aniversarios, funerales, etc. ${ }^{30}$. Todo ello termina por transmitir una sensación casi de culto, derivada del empleo de una terminología religiosa («mártires», «altar de la oposición», etc.) que revela una concepción moralista de la política ${ }^{31}$. Aunque la IPU era exhaustiva en la reivindicación de los líderes sacrificados por su causa, el búlgaro Nicolas Petkov (1896-1947) se convirtió en el epítome de todos ellos, al ser ejecutado por oponerse a la colaboración con los comunistas y negarse a aceptar una

30 Por ejemplo, el acto conmemorativo celebrado en Nueva York con ocasión del décimo aniversario de la victoria electoral en Hungría del Partido de los Pequeños Cultivadores. IPUMB XI, 1955, p. 18.

31 Ver entre otros muchos "Les Martyrs de la Paysannerie pour la Démocratie», en Union Internationale Paysanne (1950): 7. 
pena menor a cambio de confesar ser un agente occidental. El secretario de la IPU (y simultáneamente presidente del Comité Nacional Búlgaro) G. Dimitrov calificó su muerte como "asesinato judicial» por orden de Stalin, y a partir de entonces anualmente se celebraría un homenaje en septiembre para perpetuar su memoria y denunciar casos similares ${ }^{32}$. Significativamente, se establecería una conexión entre el asesinato de Aleksandar Stambolijski en 1923 durante el golpe de Estado que puso fin a su gobierno y la ejecución de Petkov un cuarto de siglo después para remachar el sentido de continuidad histórica ${ }^{33}$.

La reivindicación de sus predecesores de entreguerras se plasmaba también en la defensa de su pedigrí democrático, frente a la acusación desde los regímenes comunistas (recuperando el argumentario de la III Internacional) de ser criptofascistas ${ }^{34}$. Para contrarrestarlo se publicaron numerosos artículos en los cuales se trazaba la trayectoria de dirigentes agrarios perseguidos durante la ocupación nazi, estableciendo por cierto, así por yuxtaposición, un paralelismo evidente entre fascismo y comunismo en el que luego nos detendremos con más detalle ${ }^{35}$.

Al proclamarse herederos de la Oficina de Praga de Entreguerras y de los partidos que la componían, los dirigentes de la IPU insistieron lógicamente en desmarcarse de los partidos agrarios que en algunos países fueron creados como complemento del partido comunista e instrumento de captación de la población rural. Desde las páginas del boletín se atacó repetidamente a estos partidos como meros apéndices u hojas de parra de las dictaduras comunistas

32 BDIC, Caja 5406/1-2.

33 BUIP, I, 4-5, «À la memoire...», p. 57.

34 Son representativas las palabras que dedica Gomulka en su discurso en el III Congreso del Partido Campesino Polaco (aliado del partido comunista) en 1959, donde califica a Mikolajczyk de ser un político «de tendencias derechistas y burguesas» y de ya no ser más que «un político acabado que vivía en Occidente»; T. Ciedplak, "A Party of Stooges in the Service of Communism»; IPUMB II, 1960, pp. 12-15. Nada más fundarse la IPU el periódico polaco Dviennik Ludowy ya les dedicó una serie de artículos ("Los campesinos de Wall Street») acusándoles de traidores, agentes de los servicios secretos y en concreto a Macek de colaboracionista con los nazis. Pueden consultarse en la Fundación Hoover (fondo Mikolajczyk), documento 1002.

35 Por ejemplo, Rutaj (1948: 8) o las semblanzas de Wincenty Witos (1874-1945), el hombre fuerte del partido campesino polaco en entreguerras que se negó a negociar con los alemanes pese a ser encarcelado, o el líder del partido campesino esloveno Ivan Pucelj, que murió en Dachau en 1945. BUIP IX, 1955, pp. 13-17. El único caso en el que las acusaciones pueden tener fundamento es el de algún dirigente de los partidos agrarios bálticos. Simpson (1988). 
para engañar a los campesinos y poder imponer políticas impopulares que subordinaban el sector agrario al industrial, en particular la colectivización. La IPU los denuncia periódicamente como profanadores de la verdadera tradición agrarista de la que ella sería la legítima representante, y del mismo modo se reacciona airadamente contra la apropiación por los regímenes comunistas de determinadas figuras, como era el caso de Stambolijski, a quien se dedicó una avenida en Sofía y a quien se erigió una estatua frente a la sede del partido agrario o BZNS depurando su biografía de elementos incómodos como sus choques con el partido comunista y la pasividad de este ante el golpe que puso fin a su gobierno (y a su vida) ${ }^{36}$. «Cadáveres políticos» $\mathrm{y}$ «marionetas» son algunos de los calificativos utilizados para caracterizar a los partidos complementarios del comunista en Bulgaria o Polonia ${ }^{37}$. En su estudio sobre el caso polaco, Zalewski (2006) rompe sin embargo con la visión predominante hasta ahora al afirmar que el Zjednoczone Stronnictwo Ludowe poseía un grado no desdeńable de autonomía en su práctica y en la elaboración del discurso y una identidad propia que no permiten considerarlo un mero satélite del partido comunista, tesis que cree quizás se pueda extrapolar a sus equivalentes en otros países.

En la publicística de la IPU apenas se menciona al Frente de Aradores rumano (1944-1953) ni al Demokratische Bauernpartei Deutschlands (Partido Campesino Democrático de Alemania), fundado en 1948. En este último caso se puede interpretar como una muestra de cierta germanofobia latente, puesto que el peso de las informaciones sobre la RDA es mucho menor que en los otros casos, no se denuncia a su pseudopartido campesino como se hace en los demás casos (en Alemania habían existido varios partidos campesinos, aunque ninguno había ingresado en la Internacional de Praga) y ocasionalmente esos sentimientos podían expresarse abiertamente. Una de esas ocasiones se registra en el cuarto congreso de la IPU (1954), en el que, como era preceptivo, cada partido presentaba un informe sobre su situación y la de su país. Al llegar su turno, el secretario general del Partido Campesino Polaco, Stanislaw Wojcik, afirma que no pueden confiar en Alemania puesto que

36 Ver por ejemplo los artículos T. Cieplak «United Peasant Party ofPoland. In the Service of Communism" y "Alexander Stambolisky and the Red Treacheries Around Him», en IPUMB VII, 1958, pp. 15-19 y 20.

37 Por ejemplo, con motivo de una declaración de los «agrarios rojos» polacos y búlgaros tras un encuentro en Sofía alabando la colectivización de tierras y la alianza de los campesinos y los obreros una vez purgados los imperialistas enemigos del pueblo como Dimitrov o Mikolajczyk; "Declaration of Bulgarian and Polish 'Red Agrarians'», IPUMB, X, 1958, pp. 17-19. 
Hitler había sido elegido democráticamente y no existían pruebas de que la RFA hubiese renegado de su pasado ni de sus planes expansionistas, «de ahí que no podamos dejar de pensar en los alemanes como una nación todavía deseosa de venganza y conquista ${ }^{38}$.

El segundo pivote sería la exaltación de la agricultura y del campesinado en todos los órdenes, como no podía ser menos y como continuación de la ideología agrarista tradicional. Aunque hasta hace unas décadas predominaba una caracterización de los partidos agrarios como conservadores en lo político y retardatarios en lo económico, actualmente la historiografía mayoritaria se inclina por una visión más positiva. Su oposición tanto al capitalismo liberal como al marxismo les situaba aparentemente en contra del mito del progreso que ambos compartían, pero en realidad sería más acertado definir su propuesta como una vía de modernización alternativa, que mantendría un sector agrario sólido que incorporaría las innovaciones técnicas y se implicaría en el mercado, pero mediante el mecanismo de control que suponía el cooperativismo en todas sus manifestaciones. La Oficina de Praga defendía una vía intermedia entre capitalismo y socialismo, basada en la propiedad privada pero con una función social (expropiación de latifundios, cooperativismo...). Sin embargo, era una falsa equidistancia, puesto que ante el socialismo la oposición era sistemática y filosófica, mientras que del capitalismo lo que se pretendía en realidad era reformarlo para mitigar algunos de sus efectos, por ejemplo estableciendo mecanismos de control de precios, limitando el individualismo mediante el fortalecimiento de lazos comunitarios (actualizados a través del cooperativismo)...

La defensa de la agricultura se basaba en argumentos prácticos (estabilidad de la economía, capacidad de fijar mano de obra en el territorio, base para industrias transformadoras...), pero iba más allá, puesto que se concebía como algo que iba más allá de una actividad económica cualquiera. En las elaboraciones de los agrarios la agricultura era un modo de vida, que llevaba asociados valores que era imprescindible perpetuar, como la comunión con la naturaleza, la responsabilidad recíproca, la religiosidad, el patriotismo, el respeto por la familia y las tradiciones, etc. Esa distinción clásica (que el idioma inglés refleja a través de la dicotomía farmer/peasant) la expresa con claridad por ejemplo el croata Vladko Macek (vicepresidente de la IPU) cuando explica, en 1954, las dificultades para entenderse con los economistas estadounidenses con los que había participado en un seminario puesto que estos "consideraban al campesinado simplemente como una clase, luchando [...] por su prosperidad material. Este concepto es totalmente incorrecto. Los

38 IPUMB XI-XII, 1954, p. 43. 
campesinos en la Europa oriental y suroriental no son simplemente una clase; ellos son en sí mismos un pueblo» ${ }^{39}$.

El discurso de la IPU mantiene estas constantes, pero como es natural introduce una serie de matices derivados del contexto histórico de la Guerra Fría y del propio marco en el que desarrollaba sus actividades, que ahora era el exilio en la principal potencia del mundo capitalista. Lo primero que se observa es la acentuación del anticomunismo, que hasta entonces era ya muy marcado y no solamente en el plano teórico, puesto que se apreciaba también en la hostilidad hacia los sindicatos obreros (por su reivindicación de precios bajos para los alimentos y su pretensión de organizar a los trabajadores agrícolas). Lo que antes era un rasgo más a partir de 1947 pasa a ser la verdadera razón de ser de la IPU, una obsesión o monotema. El campesinado pasa a ser presentado como el más fiable baluarte contra la expansión del comunismo, y por ello su mantenimiento en condiciones dignas para a ser un requisito para el triunfo en la Guerra Fría. El grado de violencia requerido para imponer la colectivización en los países del otro lado del telón de acero y la resistencia pasiva con la que se saboteaban las políticas oficiales serían la mejor demostración de la incompatibilidad esencial del comunismo ("feudalismo rojo» lo denominan en varias ocasiones, al igual que se compara la situación de los miembros de los koljoses con la servidumbre) con el campesinado, que constituiría el verdadero talón de Aquiles del bloque soviético. El presidente de la IPU, tras un repaso a la situación en los diferentes países, afirmaba por ejemplo que el campesinado: «Es una fuerza enorme, obstinada, preparada a realizar sacrificios y al tanto de su situación, que ha acumulado la dinamita cuyo estallido y la fuerza de su explosión harán saltar en el momento deseado todo el sistema y hará saltar por los aires la delgada capa de la elite roja y la dictadura sanguinaria que reposa sobre ella $»^{40}$.

Si hasta la Segunda Guerra Mundial los ideólogos agraristas se habían presentado como una tercera vía entre capitalismo y socialismo, a partir de la fundación de la IPU se toma partido sin ambages por el primero y pasan a un segundo plano temas antes recurrentes como la crítica a la «industrialización» de la agricultura o la especulación sobre los precios de los alimentos. Sí se toma partido por soluciones que mantengan el libre mercado pero lo hagan

39 V. Macek, «The Ideological Position of the Croatian Peasant Party Among the Peasant Movements», IPUMB I-II, 1954, p. 3. Macek cae aquí en una metonimia muy frecuente entre los agrarios, que se consideran representantes del conjunto de su nación dado que la población rural constituiría la esencia de la misma y su parte primigenia.

40 S. Mikolajczyk, «La paysannerie et la sovietisation», BUIP, 10-11, I-II, 1951, p. 6-9. 
compatible con una agricultura familiar viable, como serían el modelo danés o la reforma agraria italiana propulsada por la Democracia Cristiana, que de hecho la IPU apoyó no solamente a través de sus publicaciones, sino organizando un foro de debate en Roma en mayo de 1958 sobre la situación de la agricultura en el bloque comunista al cual asistieron los principales representantes de la Democracia Cristiana y sus organizaciones agrarias afines, en línea con la política exterior estadounidense ${ }^{41}$. En cambio, se alaban los resultados de la agricultura basada en grandes explotaciones altamente mecanizadas con escasa mano de obra de los EE. UU., pero se afirma que sería poco deseable la extensión de su modelo a otros países puesto que crearía bolsas de paro que serían el caldo de cultivo para la propaganda comunista y en definitiva terminarían con la propia existencia del campesinado y con los valores a él asociados. En la época de la Internacional de Praga Estados Unidos nunca había sido un referente destacado para sus ideólogos, cuyo marco cultural era claramente europeo, pero la coyuntura del exilio ofrecido por Washington obligará a la IPU a dejar de lado las críticas al modelo de agricultura estadounidense al tiempo que se deshacían en elogios ante su sistema político.

El modelo de desarrollo agrario más elogiado será el escandinavo, y el nacimiento de la Comunidad Europea también va a despertar esperanzas, con matices. El contrapunto, el reverso amenazante, sería la política agraria estalinista (colectivización, precios fijados por el Estado, eliminación de la autonomía del cultivador en las decisiones, etc.). Todo partiría de la inadecuación de la lectura marxista de la agricultura y el campesinado, creando un molde teórico que requeriría dosis inauditas de coerción y violencia para encajar en él la realidad. Quien sistematiza esta incompatibilidad con más minuciosidad es el académico británico de origen rumano David Mitrany, en particular en Marx against the Peasant: a Study in Social Dogmatism (1951), que es objeto de una amplia y elogiosa reseńa y alabado en el quinto congreso de la IPU $(1956)^{42}$. Mitrany firma varios artículos en el boletín y es citado con frecuencia como autoridad, pero ideas similares (en una línea muy chayanoviana, aunque el teórico de la unidad económica campesina ejecutado en 1937 no parezca ser conocido por los hombres de la IPU) aparecen en infinidad de ocasiones. La colectivización sería una guerra contra el campesinado para erradicarlo y convertirlo en un mero siervo del Estado, y tanto la URSS como

41 BUIP XII, 1958, p. 6-9. Recientes puestas al día sobre la reforma agraria en Italia, en Bernardi y Bernardi (2011) y Misioni (2011).

42 BDIC, Caja 9/7889. La reseña (a cargo del esloveno Bogumil Vosnjak) en "The Greatest Fallacy. Remarks Upon David Mitrany's "Marx Against the Peasant", IPUMB IX, 1954, pp. 4-9. 
sus satélites eran capaces de perseverar en dicha política pese a sus pobres resultados económicos, porque el objetivo principal era terminar con un grupo social inasimilable a sus principios. La prueba sería la resistencia pasiva con la que se resistían a las imposiciones (matanza masiva de ganado antes de entregarlo al koljós, trabajo con desgana...), el partido sacado a los huertos privados o (no en el caso de la URSS) la salida masiva de mal llamados cooperativistas de los koljoses en los momentos en los que se ofrecía tal oportuni$\mathrm{dad}^{43}$. Esa era la actitud promovida por la IPU, que siempre desaconsejó el uso de la violencia por ser contraproducente.

El tercer elemento central de la cosmovisión de la IPU lo constituye su visión del comunismo, su antagonista en términos absolutos. Lo más llamativo a este respecto es el carácter monolítico e inalterable de la caracterización del mismo. A los ojos de los hombres de la IPU el comunismo era exactamente idéntico a lo largo del tiempo y del espacio, nada sustancial diferenciaría a Lenin de Stalin ni a este de Jrushchov, ni a los regímenes de Europa oriental de sus adláteres en China, Corea o Cuba. Cualquier evolución, cualquier reforma, cualquier moderación no serían más que maniobras tácticas en momentos de debilidad o bien estratagemas para engañar a sus oponentes y obtener concesiones. Por tanto la única actitud admisible por parte de Occidente era la hostilidad frontal y sin fisuras, de manera que sistemáticamente desde sus publicaciones los líderes agrarios se pronunciarán en contra del reconocimiento de los regímenes comunistas (y su admisión en la ONU), de la concesión de créditos, de las visitas de dirigentes de las democracias populares a países occidentales o de la firma de tratados de cualquier tipo (comercial, militar o cultural). A priori, sería previsible que en el estudio de una organización que pervive durante más de tres décadas fuese necesario introducir en el análisis las etapas en sus posicionamientos, pero el vaciado de las fuentes lleva a la conclusión contraria: las tesis son las mismas en los albores de la Guerra Fría que en los años setenta, cada vez más anacrónicas y ajenas a la realidad cambiante pero expresadas con la misma firmeza categórica.

Amparándose en su experiencia directa con las tácticas comunistas, los líderes exiliados advierten sin pausa a los países occidentales ante el riesgo de

43 Scott (1986) es aquí obviamente la referencia obligada, ofreciendo conceptos que Lynne Viola (1996) aplicó después magistralmente al caso de la colectivización bajo Stalin. Sin embargo, las actitudes ante los regímenes comunistas, sobre todo una vez quedó claro que iban a prolongarse en el tiempo, fueron mucho más complejas y no necesariamente marcadas solamente por la resistencia sino también por la negociación y colaboración, como se aprecia en Radu y Budeanca (2016). 
reproducir la política del appeasement con Hitler, puesto que el objetivo del comunismo era la revolución mundial y por tanto cualquier acuerdo sería provisional al faltar buena voluntad y respeto por las reglas de la diplomacia, de manera que sería respetado solamente el tiempo que les conviniese y sería aprovechado para preparar nuevas agresiones ${ }^{44}$. La ingenuidad y buena fe de los aliados occidentales ya había dado como resultado que la URSS ampliase su dominio sobre media Europa, de manera que podía considerarse que Occidente había salido "perdedor de la guerra» y «el mundo democrático» estaba «en peor situación que en $1939 »^{45}$. Cualquier concesión o la propia coexistencia pacífica tendría como efecto secundario sembrar el desánimo entre los pueblos sometidos, que se resignarían a su suerte y aceptarían los regímenes que les habían sido impuestos, contribuyéndose así por tanto a perpetuarlos ${ }^{46}$. De ahí el apoyo entusiasta a la política de contención de Truman y en particular la guerra de Corea y la preocupación en periodos de distensión.

El comunismo era capaz de utilizar cualquier medio para obtener sus objetivos y de disimular sus verdaderas intenciones, como advierte Dimitrov en su comparecencia ante el Comité de Actividades Antiamericanas en 1948 ${ }^{47}$. Lo había hecho en los países de Europa central y oriental durante el periodo de transición, cuando habían prometido que respetarían la propiedad privada campesina y de hecho habían dado su aprobación a reformas agrarias redistributivas, confiscando tierra a los grandes propietarios y a minorías étnicas, en particular alemanes. Ya una vez asegurado su dominio habían mostrado su verdadero rostro imponiendo la colectivización al estilo estalinista, aunque su alcance final terminase siendo muy desigual en los diferentes países y en ningún caso se llegase al extremo soviético. A escala internacional, la misma argucia podía ser utilizada en las relaciones exteriores, y en ningún caso quedaría más en evidencia que a la muerte de Stalin, cuando la IPU despliega una actividad frenética para que no se bajase la guardia ante las supuestas reformas aperturistas. El gobierno colegiado, el talante de Jrushchov, sus reformas económicas... todo era una ańagaza a la que incluso algunos exiliados no se mostraban inmunes, puesto que de hecho la IPU se vio obligada a desaconsejar a los refugiados

44 Por ejemplo los editoriales "Agression et politique de concession», BUIP, I-10/11, 1951, pp. 3-6 o «Mobilisation populaire», BUIP, II-4, 1952, pp. 3-6 o las conclusiones del cuarto congreso en IPUMB, XI-XII, 1954.

45 Soumar, «Editorial. Is a Workable East-West Agreement Possible?», IPUMB, I-II, 1954, pp. 1-2.

46 Swacha (2015): 302.

47 Disponible en: https://bit.ly/2NrQkPz, pp. 311-334. 
el regreso a sus países ${ }^{48}$. Los cambios en la política agraria bajo Jrushchov igualmente solo modificaban los términos de la explotación: al disolverse las estaciones de tractores y darles derecho a los koljoses a poseer sus máquinas saldrían perdiendo, puesto que tendrían que pagar el salario de los técnicos y otros gastos, los precios pagados por el Estado por los productos agrarios seguían siendo insuficientes, de igual forma que la «Campaña de las tierras vírgenes» se sostendría sobre mano de obra forzosa y el idealismo mal encauzado de los jóvenes ${ }^{49}$.

Como se ha afirmado anteriormente, tampoco se acepta modular el análisis del discurso según la variable geográfica: el comunismo mantiene su esencia a lo largo del tiempo y también del espacio, las diferencias entre los países son secundarias porque todos comparten los fines últimos y el acatamiento al modelo soviético. Se niega, pues, la mera posibilidad de un «socialismo nacional» a la Gomulka ${ }^{50}$. El caso en el que más insisten los dirigentes de la IPU es el de Tito, al que temen que Occidente, por interés en debilitar al bloque soviético, terminase viendo como no muy lejano de los laboristas británicos ${ }^{51}$.

Para terminar este apartado sería acertado detenerse en dos cuestiones independientes pero relacionadas con los puntos mencionados anteriormente. Se trata de la rusofobia y del totalitarismo. Sobre la primera, las duras experiencias personales, la presencia de exiliados bálticos y el peso del componente polaco explican esa imagen de Rusia, potencia de la cual intentan alejarse en la misma medida en que se proclaman integrantes de una cultura europea común $^{52}$. Si de manera recurrente se alaba al campesinado como sostén de

48 "Communists lure refugees home», IPUMB, V, 1956, pp. 3-7. Se trata de la reproducción de una entrevista por radio a Mikolajczyk en respuesta a una campaña en forma de folletos, cartas de familiares y declaraciones de altos funcionarios comunistas.

49 H.B., "Current Soviet Agricultural Reform. A New Propaganda Move», IPUMB VIII, 1958, pp. 23-24. Una reconsideración reciente de estas políticas en Smith (2014).

50 Por ejemplo, en respuesta a las esperanzas expresadas en el seno de la socialdemocracia en el sentido de que iría en aumento la autonomía con respecto a Moscú, el artículo de Dimitrov «Contrasting Views on National Communism», IPUMB III, 1958, pp. 4-7.

51 Véanse los análisis sobre el titismo por parte de los agrarios croatas y serbios en el segundo congreso; Union International Paysanne (1950): 46-55. Más adelante solicitarán a Eisenhower que se anule la invitación a Tito para visitar EE. UU.; IPUMB XI-XII, 1956, pp. 48-49. Tampoco apreciaban diferencias sustanciales en política agraria con los países satélites; M. Tupanjanin, «Yugoslavia Sets Example of Failure of Communist System of Farming», IPUMB, I-II, 1954, pp. 6-8.

52 Swacha (2015). 
una vía democrática peculiar en la mitad oriental de Europa, el campesinado ruso (se emplea este término y no "soviético») quedaría al margen porque el régimen zarista y luego el bolchevique le habían privado del aprendizaje previo a través del cooperativismo y los partidos agrarios. El resultado sería el atraso cultural y social del campesinado ruso frente al de los países sometidos ahora a Moscú, que irónicamente se presentaba como modelo a imitar en cuestiones agrarias ${ }^{53}$. Los hombres de la IPU establecían un nexo de continuidad en muchos aspectos entre el régimen zarista y el soviético, como la rusificación forzosa o la falta de libertades. Del mismo modo, bajo el internacionalismo propagandístico señalaban la fuerza del nacionalismo ruso como motor oculto del proyecto expansionista soviético, que en realidad sería una forma de neocolonialismo en expansión paradójicamente en la época en que el colonialismo clásico estaba desapareciendo ${ }^{54}$.

El ańadido final lo constituían los resentimientos creados durante la guerra y la inmediata posguerra, en especial en el caso de los polacos. Desde el mismo instante de su creación, la IPU recordará a la opinión pública occidental los aspectos más polémicos de la actuación de la URSS durante la Segunda Guerra Mundial, como el pacto germano-soviético, las deportaciones en los países bálticos en 1939-41 o la inacción ante el alzamiento de Varsovia. Sin embargo, el tema en el que más se incidía era la masacre de Katyn, sobre la cual todavía existía controversia, y no había sido refutada la versión soviética que la atribuía a los alemanes y que por conveniencia había sido aceptada por EE. UU. durante el conflicto 55 . Terminado este, las organizaciones polacas, y en particular Stanislaw Mikolajczyk, en 1949 impulsaron un «Comité americano para la investigación de la masacre de Katyn», que logró dos ańos después la formación en la Cámara de Representantes de la US Congressional Enquiry o Madden Committee, que en su informe final un año después atribuyó la responsabilidad al Gobierno soviético, aunque nunca se llevó a cabo su recomendación de que se crease un tribunal internacional para juzgar los hechos $^{56}$.

53 Rutaj (1948): 8.

54 M. Hodza, «Europe at the Crossroads» (reproducción de un memorándum redactado en 1944 para el Departamento de Estado de EE. UU.), IPUMB I-II, 1954, pp. 14-18; H. Blazas, "A Few Aspects of Soviet Colonialism», IPUMB, XI, 1955, pp. $12-15$.

55 S. Mikolajczyk, "Le sovietisme et les nations de derriere le rideau de fer», BUIP 1-3, 1950, pp. 8-12. Sobre la matanza y sus implicaciones hasta hoy en día, Etkind (2012).

56 Abundante documentación sobre la implicación del presidente de la IPU en la campaña en Fundación Hoover, en particular caja 154. 
El segundo argumento añadido se refiere a la contribución de la IPU a la popularización del término "totalitarismo" ${ }^{57}$. Este cuenta con una genealogía que se remonta a 1923 en el ámbito del exilio antifascista en Francia y algunos autores lo extienden a la URSS a partir de la colectivización forzosa y los juicios de Moscú en los ańos treinta, pero a partir de la entrada en la guerra del lado aliado el término cae en desuso y la analogía entre fascismo y comunismo no se retoma hasta los inicios de la Guerra Fría en consonancia con la doctrina Truman, hasta popularizarse definitivamente con la publicación en 1951 de Los orígenes del totalitarismo de Hannah Arendt. Entre los agraristas del exilio la comparación entre ambos tipos de regímenes fue moneda corriente desde el primer momento. Ferenc Nagy la establece (por el agresivo expansionismo de ambos) en la primera página de su The Struggle Behind the Iron Curtain, y lo mismo se hace en el folleto de presentación de la organización cuando se afirma que el final de la guerra «no significó la libertad sino más bien el cambio del imperialismo totalitario alemán por el de la Rusia soviética ${ }^{58}$. En la prensa y folletos de la IPU abundarán expresiones como "fascismo rojo" y se equipararán los Lager con el gulag y cualquier apertura hacia la URSS con el Pacto de Múnich con Hitler ${ }^{59}$. La asociación llegaba a extremos como referirse a George Dimitrov como «actual Gauleiter de Moscú y dictador de Bulgaria» en una conferencia de prensa en Washington en septiembre de 1948 para condenar el «asesinato judicial» del líder agrario búlgaro Petkov ${ }^{60}$.

\section{INFLUENCIA Y ACTIVIDADES}

A primera vista, la IPU podría merecer apenas una nota a pie en la crónica de la Guerra Fría, un grupo de derrotados de la historia alejados de sus países y de toda capacidad de influencia real en los acontecimientos, nostálgicos de un pasado que nunca volvería puesto que sus bases materiales y

57 Un excelente estado de la cuestión en Traverso (2002), y para EE. UU., Engermann (2009): 206. La IPU encaja en las pautas señaladas por Adler y Paterson (1970), como el uso del término "fascismo rojo» o las referencias al appeasement o Múnich.

58 Nagy (1948): VII; Rutaj (1948): 8.

59 «Derrière le rideau de fer», BUIP II-5, 1951, p. 13. En su primer informe como secretario de la IPU, Dimitrov (Union International Paysanne, 1950: 17) afirmará que las dictaduras comunistas «atacaron a las organizaciones campesinas con un grado de violencia incomparablemente mayor que el que habían empleado los nazis».

60 BDIC, Caja 5406, 1-2. 
culturales estaban siendo arrasadas por el proyecto industrializador y la ingeniería social de los regímenes comunistas tras la partición de Europa.

Con todo, conviene no olvidar una serie de factores en el haber de la IPU que enumeraremos a continuación, pero antes resulta imprescindible dejar de lado el ventajismo de la perspectiva desde el presente. Actualmente sabemos que los exiliados agrarios nunca retomarían su lugar en los países que se habían visto forzados a abandonar, pero en los años cincuenta podían albergarse dudas sobre ello. Después de todo, muchos de entre ellos habían sobrevivido en el exilio (británico por lo general) durante los años en que el dominio nazi sobre el continente parecía incontestable. Más tarde, los episodios de resistencia contra los regímenes satélites de Moscú y en especial el de Hungría en 1956 pudieron interpretarse como presagios de la caída de unos gobiernos que no contaban con el apoyo de la mayor parte de los ciudadanos y basaban su predominio en la coerción y en la amenaza de una intervención armada soviética.

El primero de los activos de la IPU eran precisamente sus dirigentes. La mayor parte de ellos habían desempeñado altos cargos en los gobiernos de sus países hasta pocos años antes, bien antes de la guerra, bien durante la misma en los gobiernos en el exilio, bien en el breve periodo anterior a la toma del poder por los partidos comunistas, acumulando un considerable capital político. Sin afán de exhaustividad, su presidente Stanislaw Mikolajczyk fue primer ministro del Gobierno polaco en el exilio tras la muerte de Sikorski en julio de 1943 y vicepresidente y ministro de Agricultura en el primer Gobierno de postguerra. Mikolajczyk había negociado directamente con Churchill o Stalin durante la guerra, y al igual que otros de líderes agrarios, pero probablemente en mayor medida que cualquiera de ellos, estaba en condiciones de recurrir a una amplia red de amigos y conocidos en la alta política internacional. El vicepresidente Ferenc Nagy (1903-1979) había sido presidente de la Asamblea Nacional en 1945-46 y primer ministro de Hungría en 1946-47. Fedor Hodza, ministro en diversos gabinetes checoslovacos en Praga o en el exilio londinense; el croata Vladko Macek, vicepresidente del Gobierno yugoslavo entre 1938 y 1941; Milan Gavrilovic (1882-1976), embajador de Yugoslavia en la URSS al inicio de la Segunda Guerra Mundial, o el lituano Kazys Grinius (1866-1950), presidente del Gobierno (1920) y de la República (1926) hasta ser destituido de resultas del golpe de Estado de diciembre de ese ańo, por citar solamente los más relevantes.

Un segundo factor era su popularidad entre las comunidades de ciudadanos estadounidenses de ascendencia centroeuropea o de Europa oriental, incrementadas además tras la imposición de los regímenes comunistas por miles de exiliados. El peso de estos votantes era particularmente acusado en la región de 
los Grandes Lagos, con la comunidad polaca como paradigma pero sin olvidar a búlgaros, yugoslavos o húngaros. Los dirigentes de la IPU compaginaban esa actividad con su presencia en los gobiernos en el exilio y en organizaciones étnicas de todo tipo, y contaban con el apoyo público de congresistas de su mismo origen. El propio Mikolajczyk presidió entre 1950 y su fallecimiento el Comité Nacional Democrático Polaco, y al morir el representante por Illinois Ed Derwinski hace su elegía en el Congreso ${ }^{61}$. En diferentes ocasiones congresistas de origen polaco de los estados de los Grandes Lagos presentaron iniciativas apoyándose explícitamente en declaraciones o documentos de la IPU ${ }^{62}$.

En tercer lugar, en unos EE. UU. que se veían compelidos a afrontar una confrontación por la supremacía mundial con el bloque comunista el conocimiento de primera mano que atesoraban los partidos y líderes agrupados bajo el paraguas de la IPU tenía un enorme valor. Las páginas del boletín de la IPU ofrecían información actualizada de todo lo que sucedía en sus países de origen y en la URSS gracias a las noticias aportadas por exiliados recientes o desertores, los contactos clandestinos a través de las fronteras y al manejo de publicística oficial. De ahí que se pudiesen ofrecer documentados reportajes sobre los congresos de los partidos comunistas, la evolución de las cosechas, los avatares de la colectivización, etc., en particular en una sección fija denominada «We Lift the Iron Curtain». También se reseñaban las principales obras que se iban publicando sobre esa región del mundo. Un lector del boletín de la IPU podía encontrarse por ejemplo con una crónica de la caída en desgracia de Milovan Djilas redactada por personas que le habían conocido personalmente y con un análisis de su tesis sobre la burocracia como nueva clase. ${ }^{63}$ En ese momento ni en la Administración ni en el mundo académico estadounidense abundaban las personas que dominasen los idiomas ni familiarizadas con la economía, la política o la historia no solo de la URSS, sino también de sus países satélites ${ }^{64}$. De ahí que, por ejemplo, la sovietología en los EE. UU. naciese marcada por la

6124 de abril de 1967, Congressional Record-House, p.10521.

62 Por ejemplo, Fundación Hoover, documento 957 (discurso del representante republicano por Connecticut Antoni Sadlak en mayo de 1955 instando a no bajar la guardia tras la muerte de Stalin); documento 989 (discurso del representante demócrata por Michigan John D. Dingell en marzo de 1956 que cita un telegrama de la IPU a Jrushchov).

63 S. Simtch (pseudónimo), «Tito’s Difficulties», IPUMB, I-II, 1954, pp. 9; 16-17B. Soumar, «Djilas Learns About Communism», IPUMB, IX, 1957.

64 Según Engermann (2009: 13) en 1946 el Gobierno de EE. UU. contaba únicamente con dos docenas de expertos en la URSS y un número todavía menor para el resto de Europa central y oriental y lo mismo pasaba con la CIA en sus primeros ańos. 
presencia de académicos polacos que en opinión de Martin Malia o Nowak le transmitieron una visión distorsionada de la URSS como esencialmente imperialista, ajena a la cultura europea y continuadora en muchos aspectos de la tradición zarista, caracterización producto de sus duras experiencias vitales por una parte y de la rusofobia imperante en su país de origen ${ }^{65}$.

Por último, la presencia de los exiliados agrarios en suelo norteamericano suponía un as en la manga para Estados Unidos si cambiaban las tornas y al tiempo, un elemento de deslegitimación de los regímenes comunistas a través de la constante crítica ejercida contra ellos a través de variadas acciones que serán analizadas a continuación.

El abanico de actividades impulsadas por la IPU fue muy considerable y ha sido recogido meticulosamente por Arkadius Indraszczyk, lo cual nos exime de extendernos más de lo imprescindible ${ }^{66}$. Además de sus propios congresos, la IPU impulsó casi doscientas reuniones o conferencias en los más diversos países, entre la primera en octubre de 1949 en Londres para dar a conocer la organización hasta las últimas en diferentes ciudades europeas en 1969-1971 sobre la invasión de Checoslovaquia y la situación de la agricultura en el bloque soviético. Presentó numerosos memoranda ante las Naciones Unidas denunciando los abusos de los regímenes comunistas, tanto los relacionados con los procesos de colectivización de la tierra como la represión de disidentes o el trato a figuras relevantes como el cardenal húngaro Mindszenty, aunque el veto soviético les garantizaba un corto recorrido. Asimismo colaboró con un gran número de organizaciones como la Assembly of Captive European Nations (de la que Dimitrov fue vicepresidente y presidente a partir de 1962), el Consejo de Europa, el Movimiento Europeo (lo que explica por cierto la intervención de Salvador de Madariaga en el quinto congreso de la IPU en París y su colaboración con varios artículos en su boletín), la Conferencia de la Agricultura Europea, la Federación Internacional de Productores Agrícolas o el Congreso Católico para la Vida Rural, además de las de exiliados de sus respectivos países en las que muchos de sus líderes doblaban cargos. Mención aparte merece la participación regular en las emisiones de Radio Free Europe, que radiaba al otro lado del telón de acero las conclusiones de sus congresos y entrevistas regulares a los principales dirigentes de la IPU ${ }^{67}$.

65 Malia (2000): 413; Nowak (2015).

66 Indraszczyk (2013).

67 Johnson y Parta (2010: 345) calculan a partir de archivos estatales y fuente oral que un tercio de la población adulta soviética y la mitad de la de los partidos satélites escuchaba esta emisora en los ańos cincuenta, a lo que habría que sumar el efecto del boca a boca. 
Una cuestión de fondo que nunca se llegó a resolver es el sentido final estratégico de las acciones emprendidas por la IPU. Por un lado, ante el potencial destructor de ambas superpotencias no se consideraba deseable un conflicto armado para poner fin a la supremacía soviética. Por otro, también se ponía énfasis (tal era la línea también de Radio Free Europe) en desaconsejar las acciones violentas o de oposición directa, cuya consecuencia sería una represión implacable, como quedó de manifiesto en toda su evidencia tras los sucesos de Hungría de $1956^{68}$. La vía negociadora era desechada, como hemos visto, pues para los exiliados agrarios sería en último término utilizada por los regímenes comunistas para consolidar su poder y obtener nuevas concesiones de Occidente. ¿Qué vía concreta se auspiciaba, pues? La inconcreción de la respuesta da la medida, en último término, de la impotencia política de la IPU, puesto que se auspiciaba la resistencia pasiva y el mantenimiento de la autonomía de los individuos frente a las presiones y los dogmas oficiales. Una postura de gran nitidez moral pero escasamente práctica, que dejaba como una única salida para la derrota del comunismo un lento desgaste por su propias contradicciones e insuficiencias que culminase en su desplome final, una esperanza que terminaría por confirmarse, pero cuando la IPU había dejado ya de existir. La única vía real de influencia a nivel político era a través de la política exterior de las potencias occidentales y en particular de la estadounidense, lo cual en último término suponía una limitada capacidad de iniciativa propia.

\section{EPÍlOGO}

En la segunda mitad de los años sesenta el boletín de la IPU, su principal canal de difusión, pasa a publicarse solamente dos veces al año. Los fundadores de la IPU ${ }^{69}$ van envejeciendo y falleciendo sin que se produzca un relevo generacional. Mikolajczyk debe ceder la presidencia a Nagy en el octavo congreso (1964), pero su sucesor estaba aquejado a su vez de problemas de salud que se suman a las disputas personales ${ }^{70}$. En 1971 aparece el último número del boletín, tras veintiún años ininterrumpidos. El editorial de despedida afirmaba que la oficina de Nueva York cerraba sus puertas pero que la de

\footnotetext{
68 Dimitrov (1957).

69 El liderazgo de los partidos agrarios era monolíticamente masculino con una única excepción, la de Alena Devenis, que asumió la representación del lituano por la enfermedad de Kazys Grinius a partir del segundo congreso.

70 Indraszczyk (2013): 221.
} 
Washington seguiría funcionando, y de hecho todavía se organizó un simposio en mayo de ese año en París en defensa de la agricultura familiar y se envió una delegación a la vigésimo tercera asamblea general de la Conferencia de la Agricultura Europea (CEA) en octubre en Tenerife ${ }^{71}$. A partir de ahí se deja de tener noticia de la organización hasta que en 1978 se registra un último intento por refundarla y la última mención conocida es el envío de una delegación, no se sabe hasta qué punto representativa, a actividades de la CEA en $1986^{72}$.

La IPU no llegó a ver la caída del Muro ni el desplome de los regímenes contra los que habían luchado en la medida de sus fuerzas. Algunos artículos en su boletín intentaban preparar el incierto futuro poscomunista, como alguno que estudiaba el desmantelamiento de la agricultura colectivizada o la reorganización política de la región a partir de la reinstauración de regímenes democráticos y un proceso de integración supranacional ${ }^{73}$. Sin embargo, la realidad posterior a 1989 poco tuvo que ver con los sueńos de los exiliados agrarios ni mucho menos con el mundo que habían dejado atrás en los años cuarenta. La agricultura ha pasado a tener un peso secundario y los partidos agrarios reconstituidos juegan un papel a años luz del que desempeñaron en entreguerras $^{74}$. Los líderes de la IPU mostraron una firmeza y una coherencia férreas a lo largo de varias décadas en la defensa de sus postulados, pero la realidad de sus países había cambiado drásticamente en su ausencia y las patrias que habían dejado atrás en los años cuarenta habían dejado de existir, el cruel destino de los exiliados.

\section{Bibliografía}

Adler, L. K. y Paterson, T. G. (1970). Red Fascism. The Merger of Nazi Germany and Soviet Russia in the American Image of Totalitarism. American Historical Review, LXXV (4), 1046-1064. Disponible en: https://doi.org/10.2307/1852269.

Agrarian Problems From the Baltic to the Aegean. Discussion of a Peasant Programme (1944). London: The Royal Institute of International Affairs.

Applebaum, A. (2014). El telón de acero. La destrucción de Europa del Este. 1944-1956. Barcelona: Debate.

IPUMB, 1971.

72 Indraszczyk (2013): 221.

73 Stepka (2015).

74 Como se puede apreciar en el panorama ofrecido en De Waele y Seiler (2009). 
Bernardi, E. y Bernardi, L. (2011). Estados Unidos y la reforma agraria italiana. Historia Agraria, 54, 141-174.

Borrás, S. M., Edelman, M. y Kay, C. (2008). Transnational Agrarian Movements: Origins and Politics, Campaigns and Impacts. Journal of Agrarian Change, 8, 169-204. Disponible en: https://doi.org/10.1111/j.1471-0366.2008.00167.x.

Cabo, M. (2018). Los partidos agrarios en Europa hasta 1945. En J.M. Lana y D. Soto (eds.). Del pasado al futuro como problema. La historia agraria española en el siglo XXI (en prensa). Pamplona: Universidad Pública de Navarra/SEHA-PUZ.

De Waele, J. M. y Seiler, D. L. (eds.) (2009). Les partis agrariens et paysans en Europe. Bruxelles: Éditions de l'Université de Bruxelles.

Dimitrov, G. M. (1957). Inferences from the Hungarian Revolution. New York: IPU.

Engermann, D. C. (2009). Know Your Enemy. The Rise and Fall of America's Soviet Experts. Oxford: Oxford UP.

Etkind, A. (ed.) (2012). Remembering Katyn. Cambridge: Polity Press.

Faraldo, J. M. (2014). Terror y sueño. Europa del Este tras 1945. En J. Rodrigo (ed). Políticas de la violencia. Europa siglo XX (pp. 401-422). Zaragoza: Prensas de la Universidad de Zaragoza.

Gaddis, J. L. (2008). La Guerra Fría. Barcelona: RBA Editores.

Gollwitzer, H. (ed.) (1977). Europäische Bauernparteien im 20.Jahrhundert. Stuttgart: Fischer. Disponible en: https://doi.org/10.1515/9783110509281.

Haushofer, H. (1977). Die internationale Organisation der Bauernparteien. En H. Gollwitzer (ed.), Europäische Bauernparteien im 20.Jahrhundert (pp. 668-690). Stuttgart: Fischer. Disponible en: https://doi.org/10.1515/9783110509281-021.

Indraszczyk, A. (2013). The Cooperation of Peasant Parties from Central and Eastern Europe in Exile after 1945. En A. Mazurkiewicz (ed.). East Central Europe in Exile Volume 2: Transatlantic Identities (pp. 93-226). Newcastle: Cambridge Scholars Publishing.

Jackson, G. D. (1966). Comintern and Peasant in East Europe, 1919-1930. New York: Columbia UP.

Johnson, A. R. y Parta, R. E. (eds.) (2010). Cold War Broadcasting. Impact on the Soviet Union and Eastern Europe. Budapest: Central European UP. Disponible en: https://doi. org/10.7829/9789639776807johnson.

Kubu, E. y Sousa, J. (2010). Wiener Grüne Internationale-eine mitteleuropäische Transfergeschichte?". En H. Schulz y A. Harre (eds.), Bauerngesellschaften auf dem Weg in die Moderne. Agrarismus in Ostmitteleuropa 1880 bis 1960 (pp. 243-256). Wiesbaden: Harrassowitz Verlag.

Leffler, M. P. y Westad, O. A. (eds.) (2011). The Cold War. Volume I. Origins. Cambridge: Cambridge UP.

Malia, M. (2000). Russia Under Western Eyes. Cambridge: Harvard UP.

Misioni, S. (2011). Colonización interior y democracia: la reforma agraria italiana de 1950 . Historia agraria, 54, 105-140.

Moser, Charles A. (1979). Dimitrov of Bulgaria. Ottawa (Illinois): Caroline House Publishers.

Nagy, F. (1948). The Struggle Behind the Iron Curtain. New York: The Macmillan Company.

Nowak, A. (2015). A "Polish Connection" in American Sovietology or the Old Homeland Enmities in the New Host Country Humanities. En M. Zadencka, A. Plakans y A. 
Lawaty (eds.). East and Central European History Writing in Exile 1939-1989 (pp. 374395).Leiden: Brill/Rodopi. Disponible en: https://doi.org/10.1163/9789004299696_021.

Radu, S. y Budeanca, C. (eds.) (2016). Countryside and Communism in Eastern Europe. Zürich: Lit. Verlag.

Ruschke, R. (2015). Useful Enemies: America's Open Door Policy for Nazi War Criminals. New York: Delphinium Books.

Rutaj, J. (1948). Peasant International in Action. London: IPU.

Saunders, F.S. (2001). La CIA y la guerra fría cultural. Madrid: Debate.

Scott, J. C. (1986). Everyday Forms of Peasant Resistence. Journal of Peasant Studies, 13 (2), 5-35. Disponible en: https://doi.org/10.1080/03066158608438289.

Simpson, C. (1988). Blowback: America's Recruitment of Nazis and its Effects on the Cold War. London: Weidenfeld andNicolson.

Smith, J. L. (2014). Works in Progress. Plans and Realities on Soviet Farms, 1930-1963. New Haven:YaleUP.Disponibleen:https://doi.org/10.12987/yale/9780300200690.001.0001.

Smutný, Z. (2010). Tzv. Zelená internacionála a politické procesy v Československu po druhé svétové válce (La llamada Internacional Verde y los procesos políticos en Checoslovaquia tras la Segunda Guerra Mundial) [tesina de licenciatura inédita]. Universidad Carolina de Praga. Disponible en https://is.cuni.cz/webapps/zzp/detail/67326/.

Stepka, S. (2015). Attitude of the International Peasant Union to Communism (1947-1989). En J. Rychlík, L. Holec y M. Pehr (eds.). Agrarismus ve stredni východni Evrope 19. A 20 (pp. 295-305). Praga: Století.

Swacha, P. (2015). European Integration in the International Peasant Union Concepts. En J. Rychlík, L. Holec y M. Pehr (eds.). Agrarismus ve stredni východni Evrope 19. A 20 (pp. 281-294). Praha: Století.

Tismaneanu, V. (ed.) (2009). Stalinism Revisited. The Establishment of Communist Regimes in East-Central Europe. Budapest: CEU Press.

Traverso, E. (2002). El totalitarisme. Història d'un debat. Valencia: Universitat de València.

Union International Paysanne (1950). La bataille de la paysannerie pour la liberté et la democratie. Premier et Second Congrès de l'Internationale Paysanne Reconstituée. Washington.

Urwin, D. W. (1980). From Ploughshare to Ballotbox. The Politics of Agrarian Defence in Europe. Oslo: Universitetsforlaget.

Valota Cavallotti, B. (1987). L'Internazionale verde tra pace e guerra. En Les Internationales et le problème de la guerre au XXe siècle. Actes du colloque de Rome (22-24 novembre 1984 (pp. 285-299). Roma: École Française de Rome.

Vigreaux, J. (2012). La faucille après le marteau. Le communisme aux champs dans l'entre-deux-guerres. Besançon: Presses Universitaires de Franche-Comté.

Viola, L. (1996). Peasant Rebels Under Stalin. Nueva York: Oxford UP.

Zalewski, F. (2006). Paysannerie et politique en Pologne. Trajectoire du Parti paysan polonais du communisme à l’après communisme, 1945-2005. París: Michel Houdiard Éditeur. 